NOTICE: this is the author's version of a work that was accepted for publication in International Journal of Production Economics. Changes resulting from the publishing process, such as peer review, editing, corrections, structural formatting, and other quality control mechanisms may not be reflected in this document. Changes may have been made to this work since it was submitted for publication. A definitive version was subsequently published in International Journal of Production Economics, Volume 154, (August 2014), DOI 10.1016/j.ijpe.2014.04.005.

The definitive version is available at: $\underline{\text { http://dx.doi.org/10.1016/.ijpe.2014.04.005 }}$ 


\title{
Demand chain management: Relationships between external antecedents, web-based integration and service innovation performance
}

\author{
Alain Yee-Loong Chong ${ }^{\mathrm{a}}$ and Li Zhou ${ }^{\mathrm{b} *}$ \\ ${ }^{a}$ Nottingham University Business School China, University of Nottingham Ningbo, China \\ ${ }^{b}$ Systems Management and Strategy Department, Business School, University of Greenwich, \\ SE10 9LS, UK
}

\begin{abstract}
This paper presents an investigation of the relationships between the factors that drive the adoption of integrated, web-based demand chain management (DCM), as well as the relationship between web-based DCM integration and service innovation performance. Data was collected from 256 companies in the health care industry. The results show that collaborative structure (e.g. competitive pressure, trust, information sharing and environmental uncertainty) and technological structure (e.g. security) have a positive and significant influence on an organization's decision to adopt web-based DCM integration. However, collaborative structure has the greatest influence by far on an organization's adoption of web-based DCM integration. The findings also show strong evidence that webbased DCM integration improves service innovation performance. We also found that webbased DCM implementation has a greater impact on service innovation performance than in organizations that only implement web-based supply or demand integration strategies. This research has important implications for organizations interested in improving their service innovation performance, as well as improving the adoption of web-based DCM integration. For example, to improve the success of web-based DCM adoption, organizations should focus on improving their collaborative structure with suppliers and customers first, before considering their technological structure. Security is also a key issue that needs to be addressed by organizations to ensure the successful adoption of web-based DCM.
\end{abstract}

Keywords: Demand chain management, web-based integration, innovation adoption, service innovation, service science

\subsection{Introduction}

Organizations today operate in an extremely competitive business environment driven by the emphasis on time and quality based competition, market uncertainties, and globalisation. In respond to the competitive environment, many organizations started to have multi-sites production networks in order to reduce costs (Chong et al., 2011). Due to the multi-sites productions, integration in supply chains becomes important for organizations. As Frohlich (2002) stated, one of the most admired organizations are those that have a tightly integrated, collaborative supply chain. Although the concept of supply chain integration has long existed, it is only due to the recent emergence of web technologies which ensure that supply chain integration can be achieved easily and practically (Bakker et al., 2008). Prior to the emergence of web technologies, organizations relied heavily on technology such as Electronic Data Interchange (EDI) to integrate their supply chain (Tai et al., 2010). However, EDI has several limitations such as the lack of consistent standard (e.g. Europe and Japan used a different EDI standard), high costs, and only transmitting data in batches. The Internet 
has solved many of the EDI implementation problems faced by organizations. The integrations between an organization and its upstream suppliers and downstream customers is known as e-supply chain integration (Akyuz and Rehan, 2009).

E-supply chain integration enable organizations to share real time information seamlessly, improve productivity, increase efficiency, improve the ability of the supply-chain to deliver faster and better products/services, improve the balance between supply and demand, and reduce the cost through better coordination and information sharing, and reduce the risks of bullwhip effects (Koh et al., 2007; Frohlich and Westbrook, 2002; Lee et al., 1997). Despite the reported benefits of e-supply chain integrations (Tai et al., 2010), there remained some important questions that are unanswered in practice in terms of successfully implementing esupply chain integrations (Caniato et al., 2009). Researches on e-technologies from the operations management (OM) perspective is so far scant as well (Cullen and Taylor, 2009; Chong and Bai, 2014). Furthermore, the performance outcome of implementing e-supply chain integrations, in particularly whether firms can have better innovation performances as a result of better supply chain remained understudy.

This paper has two aims: first, to examine the antecedents that drive the adoption of e-supply chain integration and, second, to analyse the relationship between e-supply chain integration adoption and service innovation performance. However, unlike previous studies on general e-supply chain integration, this study examined e-supply chain integration by focusing on web-based demand chain management DCM). DCM and supply chain management (SCM) are very similar in concepts, and are interchangeable except from different perspectives. With DCM, the emphasis is on the needs of the marketplace and designing the chain in order to satisfy those needs, as opposed to starting with the supplier/manufacturer and working forwards in an SC (Lun et al., 2013; Esper and Ellinger, 2010; Hilletofth, 2011). DCM is also closely related to the perspectives from market orientation which focuses on "marketing intelligence generation, market information dissemination, and market responsiveness" (Lun et al., 2013, pp. 486).

The issues addressed in this paper are critical and have several important contributions for a number of reasons. Firstly, although DCM promises many benefits in theory, in practice it can be hard to achieve due to a lack of coordination along the chain (Frohlich \& Westbrook, 2002). To solve the problem, the organization can integrate suppliers and customers via the web to facilitate the implementation of DCM, which is referred to as web-based DCM integration. On one hand, given that the primary focus of DCM is on the customers, organizations will be able to develop new products and services that better cater to customer needs. On the other hand, web-based DCM integration as a tool also brings challenges from various viewpoints, such as technological (e.g. relative advantage and security perceptions), organizational (e.g. technical and financial resources) and environmental (e.g. competitive pressure) perspectives (also known as the TOE model) (Chan et al., 2012). Although the TOE model and other adoption models, such as the diffusion of innovation model (Rogers, 1995), have been applied to examine technology adoptions, they have not been used to examine web-based DCM integration adoption. Given that the implementation of web-based DCM integration offers many advantages to firms, it remains an unanswered question as to why this tool is not adopted as often as it should be. In other words, what are the factors influencing the adoption of web-based DCM integration? Moreover, from a theoretical view, this study extends previous technology adoption models through including inter-organizational relationships such as trust and information sharing. This is important, as our findings show 
that these factors play a more prominent role in affecting organizations' adoption of webbased DCM.

Secondly, understanding the relationship between the adoption of web-based DCM integration and service innovation performance is important for both theoretical and practical reasons. Theoretically, this research can enrich the existing DCM literature by addressing a previously unexplored research area, namely whether adopting web-based DCM integration improves the service innovation performance of the organization. For practitioners, this research helps managers and decision makers to formulate strategies to motivate the adoption of web-based DCM integration in their organizations. Furthermore, as one of the key motivations for implementing DCM is to improve service performance, a positive relationship between web-based DCM integration and service innovation performance will further justify to practitioners why the adoption of web-based DCM integration should be an important business strategy in their organizations.

Thirdly, we have selected the health care industry to examine the hypotheses for three reasons: (i) unlike other industries, the health care industry demands zero fault in the product design and operations process. Hence, customer needs must be accurately transferred into product design and delivery to make products error free. It is a typical demand-driven SC (i.e. a DC); (ii) the health care industry is a leading industry in adopting the most advanced technology and techniques first. Innovation performance is one of the key measurements; (iii) the health care industry is important to the national economy and to people's livelihoods. The development of this industry is a barometer indicating governmental performance, which gives research into the area special meaning.

The rest of this paper proceeds as follows. In the next section, the literature review and the development of the hypotheses are presented. This is followed by the methodology and results. Discussions of the results and their implications are then presented.

\subsection{Literature Review and Hypotheses Development}

\subsection{E-supply chain integration via web-based DCM}

Problems due to poorly coordinated and non-integrated supply chain have been well documented in past literatures (Chong et al., 2009c). A poorly integrated supply chain will result in the Bullwhip Effect, whereby the orders to the suppliers have larger variance then the buyers' sales, and this demand distortion propagates upstream in an amplified form (Lee et al., 1997). Due to the instability in planning which is magnified backwards up to the supply chain (Lee et al., 1997), it becomes vital to control error amplified from the downstream customers to the upstream suppliers. One way to reduce the Bullwhip Effect is to balance the supply and demand across the supply chain, and this requires an integrated flow of data between the suppliers and buyers (Frohlich, 2002; Chan and Chan, 2005).

The integration of data flow can be achieved by implementing appropriate supply chain information systems (Chong et al., 2009). However, the Internet is not the first electronic link. Prior to the Internet, firms seek to integrate their supply chain through Electronic Data Interchange (EDI) on Value Added Network (VAN). However, there are some limitations of EDI on VAN such as processing information in batches, slow evolution in standard, expensive, and difficulties in implementation (Geunes et al., 2002; Chong and Ooi, 2008). 
Recent developments in internet technologies have facilitated the integration between customers and suppliers. One e-supply chain integration model which has gained the attention of researchers is web-based DCM (Frohlich and Westbrook, 2002). DCM has similar concept and is interchangeable with the definition of SCM. However, the emphasis of web-based DCM is demand-driven supply chains, and is introduced to capture deeper synergies between SCM and marketing by starting with the needs of customers and designing the chain in order to satisfy these needs (Argawal, 2012).

Given the lack of research on web-based DCM integration, the focus of the present research is on the adoption of web-based DCM integration, rather than on general DCM implementation. Frohlich and Westbrook (2002) empirically validated four web-based SC integration models, namely: those that have little or no web-based integration, those with a high level of demand integration, those with a high level of SC integration and those with a high level of web-based integration, coordinating the whole DC from the customers backwards to the suppliers. This last model is web-based DCM integration (Frohlich \& Westbrook, 2002). Previous studies have shown that DCM integration can deliver the highest level of operational performance to organizations (Rexhausen et al., 2012). However, there is still limited research to help advance the discipline in terms of what drives the adoption of web-based DCM integration and the relationship between adoption and an organization's service innovation performance.

\subsection{Diffusion of Innovation Model and the Adoption of Web-Based Demand Chain Management Integration}

Consistent with past IT technology adoption studies, this research builds its theoretical model from the diffusion of innovation (DOI) model (Rogers, 1995). DOI looks at how "an innovation is communicated through certain channels over time among the members of a social system" (Wu \& Chuang, 2009). Based on DOI, an organization's decision to implement a new information system is dependent on five main kinds of factors: innovation (new technology), individual, task, organizational and environmental (Kwon \& Zmud, 1987). In this research, these five factors are further classified into those that are related to IT attributes, or technological structures, and those that are related to maintaining relationships, or collaborative attributes (Wu \& Chuang, 2009).

Web integration involves internal, cross-functional units or external, inter-organizational integration involving customers and trading partners. However, many previous technology adoption studies in the SC have been conducted at the intra-organizational level (Wu \& Chuang, 2010). There are few studies focusing primarily on the inter-organizational level (Wu \& Chuang, 2009). The present study therefore focuses on the external, interorganizational integration between an organization and its suppliers and customers. The focus on inter-organizational integration means that technological and collaborative factors are the main concern for this research (Wu \& Chuang, 2010; Chong et al., 2009b; Ranganathan et al., 2004).

Technological attributes, such as relative advantage and complexity, have been examined extensively in various SC technologies, such as electronic data interchange (EDI), radio frequency identification (RFID) and enterprise resource planning, and have consistently been shown to have a positive relationship with an organization's decision to adopt the information system studied. Unlike other IT technologies, web-based integration in the SC also involves information sharing and the formation of collaborative relationships (Chong et al., 2009a). 
Therefore a collaborative, inter-organizational relationship between the organization and its suppliers/customers is vital (Chan et al., 2004; Chong \& Ooi, 2008; Chong et al., 2009a; Wu \& Chuang, 2010). Such collaborative relationships often include trust, communications and a willingness to share information (Chong et al., 2009b).

Based on the discussions above, this research adopts the technological and collaborative structure constructs from the DOI model and applies them to understanding an organization's decision to adopt web-based DCM integration. The next two sections further discuss the two structures and their relationships with the adoption of web-based DCM integration.

\subsubsection{Technological Structure and Web-based Demand Chain Management Integration}

Technological structure is derived from Rogers’ DOI model (Rogers, 1995; Wu \& Chuang, 2010). The three technological structure attributes selected for this study are relative advantage, complexity and compatibility.

Relative advantage is defined as the degree to which an innovation is perceived as being better than the technology it supersedes (Rogers, 1995). Before investing in a new technology, an organization assesses whether the new technology will bring more value than that preceding it. Often, the new technologies are not compatible with the existing technology, and organizations need to move to completely using the newer technology. Examples of new technologies replacing older technologies include RFID replacing barcode readers, and USB flash drives replacing floppy disk drives. In these examples, the new technology replaced the existing technology based on its superior performance (Shapiro \& Varian, 1996). In order for organizations to adopt a new information system successfully, the relative value of the information system must be made clear. There have been various findings on organizations' decisions to adopt information systems based on the advantages they offer (Chan et al., 2012). For example, Carter and Belanger (2005) found that relative advantage has no direct effect on users' adoption of e-government services, given that users are familiar with the web and do not view e-government as an innovation. At present, there are few findings in terms of how firms perceive the advantages offered by web-based DCM and whether they think that the advantages offered are sufficient for them to invest in it. Therefore, the following hypothesis is proposed:

H1a. The factor of relative advantage is significantly and positively related to the adoption of web-based DCM integration.

Complexity relates to whether an innovation is perceived as being difficult to use and understand (Chong \& Ooi, 2008). In Davis's (1989) technology acceptance model (TAM), a similar variable to complexity called "perceived ease of use" has been proposed and studied in users' acceptance of new information systems. By applying the DOI and TAM models of adoption in this research, we propose that perceptions of the complexity of web-based DCM predict organizations' intentions to adopt the system. This reflects growing evidence that complexity is a fundamental predictor of organizations' adoption of new information systems, with significant correlations to both current and future self-reported information system usage (Chan et al., 2012). Complexity and relative advantage are two of the most commonly examined variables in the study of information systems adoption. However, in the context of web-based DCM, it is still unclear whether firms' adoption decisions are influenced by their perceived complexity of the technology. This is particularly true as organizations today have more awareness of information systems, and web-based information systems are also 
perceived as being more user friendly than in the past. Thus, the following hypothesis is proposed:

H1b. The factor of complexity is significantly and negatively related to the adoption of webbased DCM integration.

Compatibility relates to whether the innovation is seen as being consistent with the past values, experience and business processes, as well as the needs of the adopters (Chong \& Ooi, 2008). Some findings on information systems adoption have suggested that organizations may need to integrate their backend or legacy systems with web-based systems; therefore, compatibility becomes crucial in adopting new information systems (Cooper \& Zmud, 1990). An example of compatibility being important in introducing a new technology can be found in Wang et al.'s (2010) study on RFID implementations. However, Low et al. (2011), in their study on cloud computing adoption in the high-tech industry, found that compatibility does not play a role in influencing firms' cloud computing adoption decisions. These contradictory findings show that perceptions on compatibility can vary for different types of technologies, and whether compatibility has a direct relationship with web-based DCM adoption remains to be investigated. Therefore, the following hypothesis is proposed:

H1c. The factor of compatibility is significantly and positively related to the adoption of webbased DCM integration.

Security is an additional variable that is included in this research to extend the existing DOI model. The main reason for this is that web integrations involve sharing information freely between trading partners and customers, and security and privacy issues have an influence on an organization's adoption decision. In previous information system adoption studies, such as those relating to collaborative commerce and e-business (Chong et al., 2009; Wu \& Chuang, 2009), it has been found that security plays a role in determining whether organizations are willing to share information, which in turn influences their willingness to adopt interorganizational systems. However, given that organizations today are more aware of web technologies and how the security risks can be minimized with proper security planning, it would be useful to examine whether organizations' web DCM adoption decisions are influenced by security issues. The following hypothesis is therefore proposed:

H1d. The factor of security is significantly and positively related to the adoption of webbased DCM integration.

\subsubsection{Collaborative Structures and Web-based Demand Chain Management Integration}

Collaboration is essential to the success of SCs (Chong et al., 2009c). Wu and Chuang (2010) and Chong et al. (2009b) state that a collaborative relationship in the SC is developed when there is a level of communication, trust, information sharing and interdependence between the SC members. Such a collaborative relationship often allows SC members to work together and share information such as product design information, forecast data and business goals. Research by Wu and Chuang (2010), Chong and Ooi (2008), Chong et al. (2009b) and Tsung (2002) found that information sharing and integration in the SC are important prerequisites for such collaborative relationships. Wu and Chuang (2010) state that the collaborative relationship is a combination structure that consists of relevant relationship attributes; they coined the term "collaborative structure". The collaborative structure attributes include peer pressure, transaction climate, environmental uncertainty and supplier interdependence (Wu \& 
Chuang, 2010). These variables have been studied either together or separately in relation to existing inter-organizational system adoptions, such as EDI and e-business (Chong \& Ooi, 2008; Chong et al., 2009b; Hart \& Saunders, 1997; Shen et al., 2004; Dhillon, 2000; Ratnasingam, 2001); however, they have not been examined in the context of web-based DCM. Although the advantages of web technologies' applications in SCM are now quite well documented, there are still few studies on whether organizations are willing to form collaborative relationships in order to achieve success in their DCs. Based on this literature, the present study adopts the following attributes to measure collaborative structure: competitive pressure, trust, information sharing and environmental uncertainty. As this study deals with DCM, which involves demand and supply integration, supplier interdependence is not included. The following paragraphs provide discussions of each of these attributes.

Competitive pressure is one of the external factors that often drive organizations to adopt a new technology (Zhu et al., 2006). Kuan and Chau (2001), for example, found that organizations adopt EDI due to the business pressure they experience. Chong et al. (2009c) also found that in order to compete, organizations in the electrical and electronics industry in Malaysia implemented collaborative technologies to improve their SCs. Wu and Chuang (2010) found that competitive pressure can influence the diffusion of e-SCM technologies in organizations. Although previous studies have supported the relationship between competitive pressure and organizations' adoption of information systems, Zhu et al. (2006) stated that competitive pressure may in fact also hinder an organization's implementation of information systems. Chong et al. (2012) also found that an organization that adopts a new technology due to competitive pressure may end up chasing the latest technologies without having time to infuse them into the organization. Therefore, whether firms adopt web-based DCM just because of competitive pressure needs to be further investigated. The following hypothesis is thus proposed:

H2a. The factor of competitive pressure is significantly and positively related to the adoption of web-based DCM integration.

Trust is one of the most important factors influencing the adoption of inter-organizational systems (Yang \& Jarvenpaa, 2005; Lam et al., 2008). Web integration for DCM requires the sharing of information among SC partners and customers, and trust plays an important role in facilitating the sharing of information in web-based DCM integration. Organizations implementing web-based DCM integration need to commit financial resources and share information, and therefore it is important that members of the SC build a long-term relationship and do not act in an opportunistic manner, even if there are short-term incentives to do so (Chong \& Ooi, 2008; Shang et al., 2005). Therefore, trust between SC members is an important factor affecting the adoption of web-based DCM integration. Although trust has been examined in relation to previous inter-organizational systems, Schlenker (2010) states that an SC is based more on the control mechanism, while a DC is based on the trust mechanism. It is therefore possible that trust plays a stronger role in the adoption of webbased DCM when compared to previous findings based on SC technologies such as EDI and e-commerce. As such, it is important to examine the role of trust in the context of web-based DCM. Therefore, we hypothesize that:

H2b. The factor of trust is significantly and positively related to the adoption of web-based DCM integration. 
A key characteristic of a successful DC is the sharing of information. For example, customers' requirements and demand forecasts need to be shared among SC members. Willingness to share information has been found to be a key decision factor for the adoption of interorganizational systems such as e-business and e-collaborations tools (Chong et al., 2009b; Chong et al., 2009c). One key reason for sharing information is to reduce uncertainty in the SC. Most previous researches have focused on SC technologies, whereby much of the sharing of information comes from business partners. However, web-based DCM involves the integration of both SC and DC processes, and therefore the sharing of information can include customers' related information, which is quite sensitive information for many organizations. As a result of this connection, this research hypothesizes that:

H2c. The factor of information sharing is significantly and positively related to the adoption of web-based DCM integration.

As the current business environment is volatile, there can be unexpected changes to requirements, materials, component supply markets and designs (Patterson et al., 2003; Wu \& Chuang, 2010). Many organizations adopt inter-organizational systems in order to reduce these environmental uncertainties (Wu \& Chuang, 2010). However, the current business environment shows that besides SC volatility, customers' requirements and demands are also changing rapidly. Customers are now faced with more choices and their preferences and decisions can change quickly. One way in which firms can address their environmental uncertainty is to better understand the customer demand through the implementation of webbased DCM. It is therefore necessary to examine whether firms are aware that web-based DCM integration can help them understand their customers better and reduce the uncertainty in their market environment. We therefore hypothesize that:

H2d. The factor of environmental uncertainty is significantly and positively related to the adoption of web-based DCM integration.

\subsection{Web-based Demand Chain Management Integration and Service Innovation Performance}

Innovation is the initiation, adoption and implementation of new ideas or activities (Chen \& Tsou, 2007; Damanpour, 1991) and "entails identifying and using opportunities to create new products, services, or work practices" (Chen \& Tsou, 2007). Innovation has received a great deal of attention as it plays a crucial role in securing sustainable competitive advantage for companies (Tushman \& Nadler, 1986). Past studies have often included the concept of service as a part of products, and service development should be included under new product development in the case of service companies (Chen \& Tsou, 2007). However, researchers and practitioners have recently focused more broadly on service innovation itself (Chen \& Tsou, 2007). Chen and Tsou (2007) state that in order for organizations to create new markets, it is important for them to implement specific service innovation practices to "develop scalar business models, manage customer experience, monitor employee performance and provide managerial process innovation”. The importance of service innovation can be observed in the way that manufacturers are beginning to change their business strategies by delivering innovative services. Examples of service innovation in manufacturing companies include RIM, which makes money through monthly subscription fees rather than from selling Blackberries, and Roll Royce, which rents airplane engines to airlines instead of selling them. 
Service innovation performance can, in general, be measured by both service product innovation and service process innovation (Chen \& Tsou, 2007). Service process innovation is the introduction of new or improved ways of designing and producing services. This can include novel ways to handle services commercially and is applied to the entire value chain process, such as gathering customer requirements, manufacturing, data processing and distribution. Service product innovation, on the other hand, involves introducing a new or improved service and entails the development, production and dissemination of new services to new consumers (Chen \& Tsou, 2007).

In order to drive innovation, Chesbrough (2003) suggests that an open innovation concept should be applied, whereby firms are encouraged to use external ideas as well as internal ones, and use both internal and external paths to market. Implementing inter-organizational systems in the SC can have an impact on an organization's internal operational processes, external intra-organizational processes and SC processes. These impacts could potentially have many positive effects on an organization's service innovation. For example, sharing information such as supplier forecasts and customer demand, and improvements in collaborations and communications between the organization and its suppliers and customers, can result in service improvement capabilities. However, empirical examinations of the relationships between inter-organizational relationship systems (such as web-based DCM) and an organization's service process innovation performance remain sparse. Thus, although it is well documented that implementations of inter-organizational systems can result in better organizational performances, it remains unknown whether such systems can lead to service innovation performance. Through implementing web-based DCM, firms may need to change or adapt their business processes, such as by finding ways to capture customer feedback, and this may lead to service process innovation. Accordingly, this research hypothesizes that:

H3. The adoption of web-based DCM integration has a positive, significant impact on an organization's service process innovation performance.

In terms of service product innovation, studies by Chen and Tsou (2007) and Vermeulen and Dankbaar (2002) have shown that implementing IT technologies enables an organization to create opportunities to introduce new services. An organization that implements web-based integration into its SC will be able to obtain various useful items of product and service information, such as information related to customer demands, sales records and customer profiles. Analysing this information will help the organization to identify and develop new product services for its customers. Furthermore, by implementing web-based DCM integration, organizations can identify the needs of customers by analysing their profiles and interacting with them, and the organizations can consequently provide customized products or services to them. Therefore, the following hypothesis is proposed:

H4. The adoption of web-based DCM integration has a positive, significant impact on an organization's service product innovation performance.

Figure 1 presents the research model used in this study, based on the literature review and hypotheses developed.

$<<$ Figure 1 about here $>>$ 


\subsection{Methodology}

\subsection{Data}

A survey instrument was developed to test the hypotheses proposed in this research. The survey was reviewed by several IT and logistics managers to verify the appropriateness of its contents and ensure it was fit for purpose. Data was collected from firms in the health care industry, which is currently one of the fastest-growing industries (Curry \& Sinclair, 2002; Chong et al., 2010). In order to stay competitive, businesses in the health care industry have applied new technologies to manage patients, personnel and inventory, as well as to streamline their processes to increase the efficiency and effectiveness of business functions. Thus, the need to achieve both efficiency through SCM and effectiveness through DCM makes them ideal candidates for web-based DCM integration and improvements in service innovation performance. Invitations to complete the surveys were sent to the operations managers, IT managers or logistics managers of the health care companies. In order to reduce bias in the surveys collected, the respondents were asked to exclude any references to their own names or those their companies.

The survey was emailed to 1,000 organizations listed in the Malaysian Medical and Health Care Directory, the Klinik2u.com portal and the Malaysian Ministry of Health web portal. The data collection process took approximately six months. One month after the emails were sent out, a reminder was sent to the companies that had not replied to the initial emails. We then phoned the companies that had not responded to our initial emails three months after the email reminders. Of the 1,000 surveys emailed out, 256 usable surveys were collected, yielding a response rate of $25.6 \%$. Our research consisted of 126 firms with fewer than 20 employees, 88 with between 20 and 50 employees, and 42 firms with more than 50 employees. In terms of turnover, 123 firms had turnovers of below RM 1 million (note: USD 1 = RM 3.00), 95 firms had turnovers of between RM 1 million and RM 5 million, and 38 firms had turnovers of more than RM 5 million.

As the response rate was not $100 \%$, there was a risk of non-response bias, which could have contaminated the reliability of the findings. A non-response bias test was therefore conducted to assess the extent of potential bias in the results (Armstrong \& Overton, 1977). The nonresponse bias was assessed by dividing the responses into three groups, namely first round (n $=115,44.92 \%)$, second round $(n=68,26.56 \%)$ and third round $(n=73,28.51 \%)$. The answers of the three groups to the survey items were compared and analysed using ANOVA. The test results indicate that there are no statistically significant differences between the mean scores of the three groups of respondents on the survey items. Therefore, this indication of non-response bias suggests that this was unlikely to be a problem in this study.

As the survey asked for self-reported data, there was also a risk that common method bias might occur. Podsakoff and Organ (1986) state that if the variables in a study all load on one factor, or if there is one factor that explains the majority of the variance, then common method variance may exist. Similar to the approach by Lai et al. (2005), we performed an exploratory factor analysis on all measurement items. Our analysis shows nine significant factors (eigenvalues greater than 1) explaining $89.57 \%$ of the variance $(40.43 \%, 10.22 \%$, $9.41 \%, 7.47 \%, 5.19 \%, 4.57 \%, 4.21 \%, 4.14$ and 3.93\% respectively, for each factor). The results suggest that there is no significant common method bias in the data set (i.e. a single factor did not emerge from the un-rotated factor solution) (Chong \& Chen, 2012). 
Partial least square (PLS) path modelling was applied to examine the research model. The sample size for this research is 256, which is relatively small for conducting covariance-based Structural Equation Modelling (SEM. However, the sample size satisfies the 1:10 ratio for PLS path modelling, as recommended by Hair et al. (2006). Given our aim of simultaneously evaluating the reliability and validity of the measures of the constructs in the model, together with estimating the relationships among these constructs, the PLS method was chosen as the better option for analysis than covariance-based SEM in this research project.

\subsection{Measurement Model Evaluation}

The items used in this study were adapted from previous studies, but were modified to include web-based demand and supply integration as the technology studied. The service innovation performance variable was measured using both service process innovation and service product innovation, which are adapted from Chen and Tsou (2007). A total of 50 questions were used to measure the variables used in this study. Responses to the items were based on a seven-point Likert scale, ranging from 1 (Strongly Disagree) to 7 (Strongly Agree). The questionnaire items are shown in Appendix 1.

The reliability of the construct measurement was evaluated by examining the composite reliability, as suggested by Gefen et al. (2011). As shown in Table 2, in all cases the composite reliability is greater than the recommended value of 0.70 .

$<<$ Table 1 about here $>>$

The convergent validity of a set of items with respect to their associated constructs is assessed by examining the factor loadings of the items on the research model's constructs. A high loading of an item on its underlying construct, and lower loadings on unrelated constructs, indicates convergent validity. The results in Table 3 show that all construct items have item loadings of more than 0.70 , thus demonstrating the reasonable convergent validity of the measurement model with respect to the model's constructs.

$<<$ Table 2 about here $>>$

Discriminant validity indicates the extent to which a given construct is different from the other constructs. Satisfactory discriminant validity is shown when a construct shares more variance with its measures (indicators) than with the other constructs in the model. A measure of variance shared between a construct and its measures is the average variance extracted (AVE), and this should be greater than the variance shared between the construct and other constructs in the model (Kijsanayotin et al., 2009). The correlation matrix for the constructs is shown in Table 2. The table provides the diagonal of the matrix, which contains the square roots of the AVEs (shown in bold), and provides a metric comparable to a correlation (the square root of the variance shared between two variables). As shown in Table 2, the diagonal elements are greater than the off-diagonal elements in the corresponding rows and columns. Thus, discriminant validity was confirmed.

\subsection{Structural Model Evaluation}

Table 4 shows the results of the structural model.

$<<$ Table 3 about here $>>$ 
The results show that security, trust, competitive pressure, information sharing and environmental uncertainty have a significant and positive relationship with the adoption of web-based DCM integration. Relative advantage, complexity and compatibility were found to have no significant relationship with the adoption of web-based DCM integration. The results also show that web-based DCM integration can enhance an organization's service process innovation and service product innovation. However, service production innovation was found to have a stronger relationship with web-based DCM integration than service process innovation.

We also examined whether web-based DCM integration mediates the effects of innovation performance in organizations, and found that web-based DCM integration has partial mediating effects on the relationships between security, competitive pressure, trust, information sharing, and environmental uncertainty, and the service innovation performances of health care organizations.

\subsection{Discussion}

In this section, the main findings are discussed in the following order: the relationships between technological and collaborative structures and the adoption of web-based DCM, and the relationships between web-based integration strategies and service process and service product innovation.

\subsection{Technological and Collaborative Structure and Adoption of Web-Based DCM}

The findings suggest that collaborative structure, in general, has a stronger influence on the adoption of web-based DCM. All the variables in the collaborative structure construct were found to have positive and significant relationships with the adoption of web-based DCM. On the other hand, only security was found to have positive and significant relationships with the adoption of web-based DCM integration. This suggests that in order for organizations to successfully integrate their DC and SC practices via the web, they need to address the collaborative relationship issues between SC members and customers. This result is consistent with the findings of similar adoption studies that have examined other interorganizational technologies, such as those by Chong et al. (2009b).

Trust was found to be the most significant collaborative structure variable. This is consistent with many previous studies on inter-organizational systems technologies (Chong \& Ooi, 2008; Wu \& Chuang, 2010). The main difference between this study and past studies is that the latter have tended to focus on the importance of trust in order to facilitate SC integration. However, the present research shows that trust is equally important when organizations are implementing DCM. When obtaining customer information and requirements, certain information needs to be shared with them. For example, customers may be asked to vote on their preferences for various proposed new designs. An organization needs to be willing to trust its customers and share information with them.

The findings from the data analysis suggest that competitive pressure is able to drive an organization's decision to adopt web-based DCM. Although web-based SCM systems such as EDI and e-business technologies have been implemented by organizations in order to remain competitive, the results show that competitive pressure is also driving organizations to adopt web-based DCM. In this sense, if an organization's main competitors are successful in using 
DCM to achieve their goals, organizations in the same arena will be very likely to respond to the pressure by adopting web-based DCM.

Information sharing among SC members is an important factor for the successful implementation of DCM. This includes key information such as customer requirements and demand forecasts. Without such information sharing with key SC members, DCM will not be successful. Willingness to share information has been found to be important in previous studies of B2B technologies and collaborative commerce (Chong et al., 2009a, 2009b). The main challenge in this regard is convincing organizations to change their mindsets to enable this sharing to occur (Ryu et al., 2009).

Environmental uncertainty plays an important role in determining collaborative structure for the adoption of web-based DCM. The findings suggest that when an organization experiences uncertainty in its business environment, and has a high level of change in its market, it is more likely to address this by adopting web-based DCM. Uncertainty in the business environment also drives organizations to work together with their suppliers and customers and to have better integrated DCM through the use of web technologies.

The results show that technological structure has less influence on the adoption of web-based DCM integration than collaborative structure does. The results suggest that organizations are more concerned with building up relationships with their SC partners than with shifting their focus to technological structure variables such as security and relative advantage.

Among the technological structure variables, only security was found to be significant. This is because implementation of the system requires the sharing of information among the SC partners on an open network. Such collaboration exposes sensitive information to potential risk, and consequently organizations need to pay more attention to security issues (Wu \& Chuang, 2010).

Relative advantage, complexity and compatibility are not significantly related to the adoption of web-based DCM. The explanation for this could be that most organizations are now familiar with internet technologies and better designed user interfaces, and know what webbased DCM integration can give them. These three factors thus no longer represent a complex subject to them. Unlike in previous studies, decision makers today are more concerned with other factors that can influence firms to progress from their initial adoption decisions to a "routinization" stage involving integration with customers and suppliers (Chong \& Chan, 2012).

\subsection{Adoption of Web-based DCM Integration and Service Process and Product Innovation}

The results show that the adoption of web-based DCM integration can improve an organization's service process and product innovation. Therefore, when an organization focuses on a web-based DCM integration strategy, with emphasis on the DC starting from customer requirements, service process and product innovation performance will improve. In terms of service process innovation, the main reason for the improvement probably lies in the fact that in order to implement DCM, organizations need new ways of interacting with customers and capturing their requirements. This could involve using tools such as Customer Relationship Management (CRM) systems and web 2.0 technologies, such as social networking tools or blogs. These new ways of interacting with customers results in improved ways of handling services through the entire value chain. An organization is therefore more 
likely to introduce new or enhanced service products by improving demand integration, typically by using CRM or customer profiling. However, the results also show that it is the implementation of DCM, with strong integration between an organization and both its suppliers and its customers, and an emphasis on customer requirements and needs, that will most improve an organization's service product innovation.

\subsection{Conclusions and Implications}

The study of web-based DCM and service innovation is a topic that is capturing the interests of researchers and academics. Several significant contributions are made by this research. The study attempts to integrate the two areas by investigating the relationships between the adoption of web-based DCM and service innovation performance, and the factors that influence organizations to adopt web-based DCM integration. It is one of the few empirical studies to focus specifically on the factors affecting the adoption of web-based DCM integration. Furthermore, it is unknown whether the implementation of web-based DCM can hinder or promote an organization's service innovation performance. Our empirical results confirm the relationship between web-based DCM and service innovation performance. In addition, our study extends previous technology adoption models and focuses not only on the technological characteristics of an innovation, but also on inter-organizational relationships such as its collaborative structures. This is significant, as our results show that collaborative structures play a more important role compared to technological structures, which are often found to be important antecedents to SCM technology adoption. Lastly, this research is significant as it was carried out in the health care industry, which is one of the most important sectors in most countries' economic development.

This research has several implications. Firstly, the adoption of web-based DCM integration can help organizations to improve their service innovations. Although past studies have tended to focus on SC integration and its impact on organizational performance, the results suggest that organizations should try to improve their web-based DCM integration whenever possible. Although further studies and replications need to be conducted to further validate the results, an organization will have a higher chance of achieving service process and service product innovation by focusing on DCM. Secondly, given that the results show that a webbased DCM strategy produces the greatest improvements in service innovation performance, the question that arises is: How can organizations improve the adoption of their web-based DCM? The findings suggest that collaborative structures involving trust, information sharing, environmental uncertainty and competitive pressure play a greater role in influencing an organization's adoption than the organization's technological structure does. Organizations should therefore focus on improving their collaborative structure with suppliers and customers first, before considering their technological structure, to improve the success of web-based DCM adoption. Furthermore, as internet technologies have become more familiar to organizations and users, many of the innovation characteristics suggested by Rogers (1995) have become less relevant (i.e. compatibility and complexity). The results on service innovation performance complement this; in this research, web-based DCM was found to have a greater impact on service innovation performance than in organizations that only implement web-based supply or demand integration strategies. Security is also a key issue that needs to be addressed by organizations to ensure the successful adoption of web-based DCM. Lastly, the present research specifically investigates the relationship between the adoption of web-based DCM integration and service innovation performance. This is an improvement on the study conducted by Chen and Tsou (2007), which focused on the adoption of general IT technologies and service innovation performance. 


\subsection{Limitations and Future Studies}

This study has several limitations and opportunities for future study. Firstly, the sample data collected for this study is relatively small. This was due to the difficulty in obtaining responses from organizations, despite various efforts to improve the response rate. However, the sample indicates no systematic non-response bias. Secondly, the data was collected within the health care industry only. Future studies could include data from other industries and compare the results between different industries. Lastly, although this research asked people who were executives in IT or logistics departments to complete the survey, future studies could consider obtaining data from executives in both IT and logistics departments. Collecting data from multiple respondents in the same organization would improve the validity of the research model. 


\section{Appendix Survey Items*}

Relative Advantage

- Web-based DCM integration improves speed of response.

- Web-based DCM integration improves service/support.

- Web-based DCM integration improves the reliability and delivery of products and services.

- Web-based DCM integration helps reduce costs.

- Web-based DCM integration helps improve inventory turnover.

Complexity

- My interaction with web-based DCM integration systems is clear and understandable.

- I believe that it is easy make web-based DCM integration systems do what I want them to do.

- Learning to operate web-based DCM integration systems is easy for me.

Compatibility

- Web-based DCM integration systems are compatible with our existing IT infrastructure.

- Web-based DCM integration systems are compatible with our customers'/suppliers' IT infrastructures.

- It is easy to integrate web-based DCM integration systems with our existing systems.

Security

- The communication security of web-based DCM integration systems affects our firm's implementation decisions.

- The communication security of web-based DCM integration system affects our firm's adoption decisions.

- I trust that web-based DCM integration systems are secure.

Competitive pressure

- We implemented web-based DCM integration due to peer pressure "to get on board".

- We implemented web-based DCM integration due to pressure from suppliers.

- We implemented web-based DCM integration due to pressure from customers.

- We implemented web-based DCM integration due to threats from traditional competitors.

Trust

- Mutual trust and faith among trading partners and customers makes web-based DCM integration adoption more likely.

- Our organization trusts that any confidential, proprietary information shared with trading 
partners through web-based DCM integration will be kept confidential.

- One must have a previous business relationship with my organization in order adopt web-based DCM integration.

Information sharing

- The introduction of web-based DCM integration entails increased visibility and transparency of business operations among trading partners and customers.

- My company is comfortable sharing our business operation information with trading partners and customers.

- The introduction of web-based DCM integration entails increased visibility and transparency of business operations among trading partners and customers.

Environmental uncertainty

- If my firm experiences a high level of market change and uncertainty, it is more likely to adopt web-based DCM integration systems.

- If the industry of which my firm is part of experiences a high level of market change and uncertainty, my firm is more likely to adopt web-based DCM integration systems.

- Due to the volatile market demands, it is important that we involve customers' inputs in the design and development of our products/services.

To what extent have you implemented web-based processes for any of the following with your suppliers?

- Integrated inventory planning

- Integrated supply chain management

- Integrated demand/forecasting

- Integrated order scheduling and tracking

To what extent have you implemented web-based processes for any of the following with your customers?

- Targeted marketing/customer profiling

- Online order taking/receipt

- Integrated demand/forecasting

- Customer relationship management

Web-based DCM integration

- Our organization uses the web to manage integration between the demand and supply processes.

- Our supply chain starts from the customers' requirements.

- We use web-based integration systems to obtain knowledge about changes in customer needs as a basis for the structural adaptation requirements of the supply chain.

- We link external, customer-facing segmentation with the internal segmentation of 
production, logistics and sourcing.

- We use web integration systems to manage the cross-functional relationships between marketing and supply functions.

Service process innovation

For the past few years, our company has often offered new practices in:

- Customer service

- Customer information inquiry and consultation

- Selling services

- Providing after-sales services

- Developing new services

- Promoting new services

- Internal administration and operations**

Service product innovation

For the past few years, our company has often:

- Revised and improved existing services

- Repackaged existing services

- Extended services

- Created and established new lines of services

*Note: Survey items adopted from Chen and Tsou (2007), Frohlich and Westbrook (2002) and Wu and Chuang (2010).

**item deleted due to low loading 


\section{References}

Agrawal, D. K., 2012. Demand chain management: factors enhancing market responsiveness capabilities. Journal of Marketing Channels, 19(2), 101-119.

Al-Qirim, N., 2008. The adoption of eCommerce communications and applications technologies in small businesses in New Zealand. Electronic Commerce Research and Applications, 6(4), 462-73.

Armstrong, J.S., Overton, T.S., 1977. Estimating Nonresponse Bias in Mail Surveys. Journal of Marketing Research, 14, 396-402.

Arora, V., Chan, F., Tiwari, M., 2010. An integrated approach for logistic and vendor managed inventory in supply chain. Expert Systems with Applications, 37(1), 39-44.

Baker, S., 2003. New consumer marketing. Chichester: John Wiley \& Sons Inc.

Bitner, M.J., Brown, S.W., 2008. The service imperative. Business horizons, 51(1), 39-46.

Brace, G., 1989, Market powertrain: an imperative to co-operation. In: Proceedings of the Commission of European Communities Partnership Between Small and Large Firms Conference. Graham and Trotman, London.

Carter, L., Belanger, F., 2005. The utilization of e-government services: citizen trust, innovation and acceptance factors.Information Systems Journal, 15(1), 5-25.

Chan, F.T.S., Chung, S., Wadhwa, S., 2004. A heuristic methodology for order distribution in a demand driven collaborative supply chain. International Journal of Production Research, 42(1), 1-19.

Chan, F., Chan, H., 2009. Effects of cascade information sharing in inventory and service level in multi-echelon supply chains. International Journal of Business Performance and Supply Chain Modelling, 1(1), 1-7.

Chan, F.T.S, Chong, A.Y., Zhou, L., 2012. An empirical investigation of factors affecting ecollaboration diffusion in SMEs. International Journal of Production Economics, 138, 329-344.

Chen, J., Tsou, H., 2007. Information technology adoption for service innovation practices and competitive advantage: the case of financial firms. Information Research, 12(3), 1368-613.

Chesbrough, H.W., 2003. Open innovation: The new imperative for creating and profiting from technology. Boston: Harvard Business Press.

Chong, A.Y.L., Chen, F.T.S., 2012. Structural equation modeling for multi-stage analysis on Radio Frequency Identification (RFID) diffusion in the health care industry. Expert Systems with Applications, 39(10), 8645 - 8654.

Chong, A.Y.L., Ooi, K.B., 2008. Adoption of interorganizational system standards in supply chains: An empirical analysis of RosettaNet standards. Industrial Management \& Data Systems, 108(4), 529-47.

Chong, A.Y.L., Ooi, K.B., Lin, B., Raman, M., 2009a. Factors affecting the adoption level of c-commerce: an empirical study. Journal of Computer Information Systems, 50(2), 1322.

Chong, A.Y.L., Ooi, K.B., Lin, B., Tang, S.Y., 2009b. Influence of interorganizational relationships on SMEs' e-business adoption. Internet Research, 19(3), 313-31.

Chong, A.Y.L., Ooi, K.B., Sohal, A., 2009c. The relationship between supply chain factors and adoption of e-Collaboration tools: An empirical examination. International Journal of Production Economics, 122(1), 150-60.

Cooper, R.B. and Zmud, R.W., 1990. Information technology implementation research: a technological diffusion approach. Management Science, 36, 123-39.

Curry, A., Sinclair, E., 2002. Assessing the quality of physiotherapy services using Servqual. International Journal of Health Care Quality Assurance, 15(5), 197 - 205. 
Damanpour, F., 1991. Organizational Innovation: A Meta-Analysis of Effects of Determinants and Moderators. The Academy of Management Journal, 34(3), 555-90.

Davis, F.D., 1989. Perceived usefulness, perceived ease of use, and user acceptance of information technology. MIS quarterly, 13(3), 319-40.

De Treville, S., Shapiro, R.D., Hameri, A.P., 2004. From supply chain to demand chain: the role of lead time reduction in improving demand chain performance. Journal of Operations Management, 21(6), 613-27.

Dhillon, G., 2000. Interpreting the adoption and use of EDI in the Portuguese clothing and textile industry. Information Management \& Computer Security, 8(4), 184-8.

Esper, T. L., Ellinger, A. E., Stank, T. P., Flint, D. J., \& Moon, M., 2010. Demand and supply integration: a conceptual framework of value creation through knowledge management. Journal of the Academy of Marketing Science, 38(1), 5-18.

Fisher, M.L., 1997. What is the right supply chain for your product? Harvard Business Review, 75(2), 105-16.

Frohlich, M.T., Westbrook, R., 2002. Demand chain management in manufacturing and services: web-based integration, drivers and performance. Journal of Operations Management, 20(6), 729-45.

Gefen, D., Rigdon, E. E., and Straub, D. W. 2011. Editor's Comment: An Update and Extension to SEM Guidelines for Administrative and Social Science Research. MIS Quarterly, 35(2), iii-xiv.

Grawe, S.J., Chen, H., Daugherty, P.J., 2009. The relationship between strategic orientation, service innovation, and performance. International Journal of Physical Distribution \& Logistics Management, 39(4), 282-300.

Gunasekaran, A., Ngai, E.W.T., 2008. Adoption of e-procurement in Hong Kong: an empirical research. International Journal of Production Economics, 113(1), 159-75.

Hair, J., Black, W., Babin, B., Anderson, R., Tatham, R., 2006. Multivariate Data Analysis. Upper Saddle River, NJ: Prentice Hall.

Hart, P., Saunders, C., 1997. Power and trust: Critical factors in the adoption and use of electronic data interchange. Organization science, 8(1), 23-42.

Hilletofth, P., 2011. Demand-supply chain management: industrial survival recipe for new decade. Industrial Management \& Data Systems, 111(2), 184 - 211.

Heikkila, J. 2002. From supply to demand chain management: efficiency and customer satisfaction. Journal of Operations Management, 20, 747-67.

Jeyaraj, A., Rottman, J.W., Lacity, M.C., 2006. A review of the predictors, linkages, and biases in IT innovation adoption research. Journal of Information Technology, 21(1), 123.

Jüttner, U., Christopher, M., Baker, S., 2007. Demand chain management-integrating marketing and supply chain management. Industrial Marketing Management, 36(3), 377-92.

Jüttner, U., Godsell1, J., Christopher, M., 2006. Demand chain alignment competence delivering value through product life cycle management. Industrial Marketing Management, 35, 989-1001.

Kijsanayotin, B., Pannarunothai, S., Speedie, S.M., 2009. Factors influencing health information technology adoption in Thailand's community health centers: applying the UTAUT model. International Journal of Medical Informatics, 78(6), 404-416.

Koh, S., Demirbag, M., Bayraktar, E., Tatoglu, E., Zaim, S., 2007. The impact of supply chain management practices on performance of SMEs. Industrial Management and Data Systems, 107(1), 103 - 24. 
Kuan, K.K.Y., Chau, P.Y.K., 2001. A perception-based model for EDI adoption in small businesses using a technology-organization-environment framework. Information \& Management, 38(8), 507-21.

Kwon, T.H., Zmud, R.W., Unifying the Fragmented Models of Information Systems Implementation. In Boland, J.R., Hirshheim, R. (eds.), 1987. Critical Issues in Information Systems Research, New York: John Wiley, 227-251.

Lai, K-H., Cheng, T.C.E., Yeung, A.C.L., 2005. Relationship stability and supplier commitment to quality. International Journal of Production Economics, 96(3), 397 410.

Lam, C., Chan, S., Ip, W., Lau, C., 2008. Collaborative supply chain network using embedded genetic algorithms. Industrial Management \& Data Systems, 108(8), 110110.

Langabeer, J. R., Rose, J., 2001. Creating Demand Driven Supply Chains: How to Profit from Demand Chain Management, 1st edition. Oxford, England: Chandos Publishing.

Levitt, J., 1960. Marketing myopia. Harvard Business Review, July/August, 45-56.

Liao, S.H, Chen, Y.N., Tseng, Y.Y., 2009. Mining demand chain knowledge of life insurance market for new product development. Expert Systems with Applications. 36, 94229437.

Low, C., Chen, Y., Wu, M., 2011. Understanding the determinants of cloud computing adoption. Industrial Management \& Data Systems, 111(7), 1006 - 1023.

Lun, Y. H., Lai, K. H., Wong, C. W., Cheng, T. C. E., 2013. Demand chain management in the container shipping service industry. International Journal of Production Economics, 141(2), 485-492.

Paton, R.A., McLaughlin, S., 2008. Services innovation: Knowledge transfer and the supply chain. European Management Journal, 26(2), 77-83.

Podsakoff, P.M., Organ, D.W., 1986. Self-reports in organizational research Problems and prospects. Journal of Management, 12(4),531-544

Mason-Jones, R., Towill, D.R., 1999. Total cycle time compression and the agile supply chain. International Journal of Production Economics, 62, 61-73.

Patterson, K.A., Grimm, C.M., Corsi, T.M., 2003. Adopting new technologies for supply chain management. Transportation Research Part E: Logistics and Transportation Review, 39(2), 95-121.

Prajogo, D.I., Sohal, A.S., 2003. The relationship between TQM practices, quality performance, and innovation performance: An empirical examination. International Journal of Quality \& Reliability Management, 20(8), 901-18.

Ranganathan, C., Dhaliwal, J.S., Teo, T.S.H., 2004. Assimilation and diffusion of web technologies in supply-chain management: an examination of key drivers and performance impacts. International Journal of Electronic Commerce, 9(1), 127-61.

Ratnasingam, P., 2001. Inter-organizational trust in EDI adoption: the case of Ford Motor Company and PBR Limited in Australia. Internet Research, 11(3), 261-9.

Rexhausen, D., Pibernik, R., Kaiser, G., 2012. Customer-facing supply chain practices-The impact of demand and distribution management on supply chain success. Journal of Operations Management, 30(4), 269-281.

Rogers, E.M., 1995. Diffusion of innovations. New York: Free Press.

Russell, D.M., Hoag, A.M., 2004. People and information technology in the supply chain: Social and organizational influences on adoption. International Journal of Physical Distribution \& Logistics Management, 34(2), 102-22.

Ryu, S.J., Tsukishima, T., Onari, H., 2009. A study on evaluation of demand informationsharing methods in supply chain. International Journal of Production Economics, 120(1), 162-75. 
Schlenker, L., 2010. Demand chain management. Working Paper. Available at: http://www.lhstech.com/chair/whitepaper/Forms/AllItems.aspx (Access on 08/11/2012).

Selen, W., Soliman, F., 2002. Operations in today's demand chain management framework. Journal of Operations Management, 20(6), 667-73.

Serve, M., Yen, D.C., Wang, J.C., Lin, B., 2002. B2B-enhanced supply chain process: toward building virtual enterprises. Business Process Management Journal, 8(3), 245-53.

Shang, R.A., Chen, C.C., Liu, Y.C., 2005. Internet EDI adoption factors: power, trust and vision. Proceedings of International Conference on E-Commerce, Xi'an, 101-108.

Shapiro,C, Varian, H.R., 1998. Information Rules: A Strategic Guide to the Network Economy. Harvard Business Review Press.

Shaw, R. and Kotler, P., 2009. Rethinking the Chain: Make marketing leaner, faster and better. Marketing Management, 18(4), 18-23.

Shen, L., Hawley, J., Dickerson, K., 2004. E-commerce adoption for supply chain management in US apparel manufacturers. Journal of Textile and Apparel Technology and Management, 4(1), 1-11.

Singh, P.J., Smith, A.J.R., 2004. Relationship between TQM and innovation: an empirical study. Journal of Manufacturing Technology Management, 15(5), 394-401.

Soliman, F., Youssef, M., 2001. The impact of some recent developments in e-business on the management of next generation manufacturing. International Journal of Operations and Production Management, 21 (5/6), 538-564.

Tornatzky, L., Fleischer, M., 1990. The process of technology innovation. New York: Lexington Books.

Tsung, F., 2002. Impact of information sharing on statistical quality control. Systems, Man and Cybernetics, Part A: Systems and Humans, IEEE Transactions on, 30(2), 211-6.

Tushman, M., Nadler, D., 1986. Organizing for innovation. California management review, 28(3), 74-92.

Vermeulen, P., Dankbaar, B., 2002. The organisation of product innovation in the financial sector. The Service Industries Journal, 22(3), 77-98.

Vollmann, T.E., Cordon, C., 1998. Building successful customer-Supplier alliances. Long range planning, 31(5), 684-94.

Vollmann, T.E., Cordon, C., Heikkila, J., 2000. Teaching supply chain management to business executives. Production and Operations Management, 9(1), 81-90.

Wadhwa, S., Rao, K., Chan, F., 2005. Flexibility-enabled lead-time reduction in flexible systems. International Journal of Production Research, 43(15), 3131-62.

Walters, D. 2006. Effectiveness and efficiency: the role of demand chain management. The international journal of logistics management, 17(1), 75-94.

Wang, Y.M., Wang, Y.S. and Yang, Y.F. 2010. Understanding the determinants of RFID adoption in the manufacturing industry. Technological Forecasting \& Social Change, 77, 803-15.

Wu, I.L., Chuang, C.H., 2010. Examining the diffusion of electronic supply chain management with external antecedents and firm performance: A multi-stage analysis. Decision Support Systems, 50 (1), 103 - 15.

Wu, I.L., Chuang, C.H., 2010. Analyzing contextual antecedents for the stage-based diffusion of electronic supply chain management. Electronic commerce research and applications, 8, $302-14$.

Yang, G., Jarvenpaa, S.L., 2005. Trust and radio frequency identification (RFID) adoption within an alliance. Proceedings of the 38th Hawaii International Conference on System Sciences, Big Island, Hawaii. 
Zhu, K., Kraemer, K.L., Xu, S., 2006. The process of innovation assimilation by firms in different countries: A technology diffusion perspective on e-business. Management Science, 52(10), 1557 - 76. 


\section{Figure captions}

Figure 1: Research Model

\section{Technological Structure}

Relative advantage

Complexity

Compatibility

Security

\section{Collaborative Structure}

Competitive pressure

Trust

Information sharing

Environmental uncertainty 
Table 1: Construct composite reliability and discriminant validity

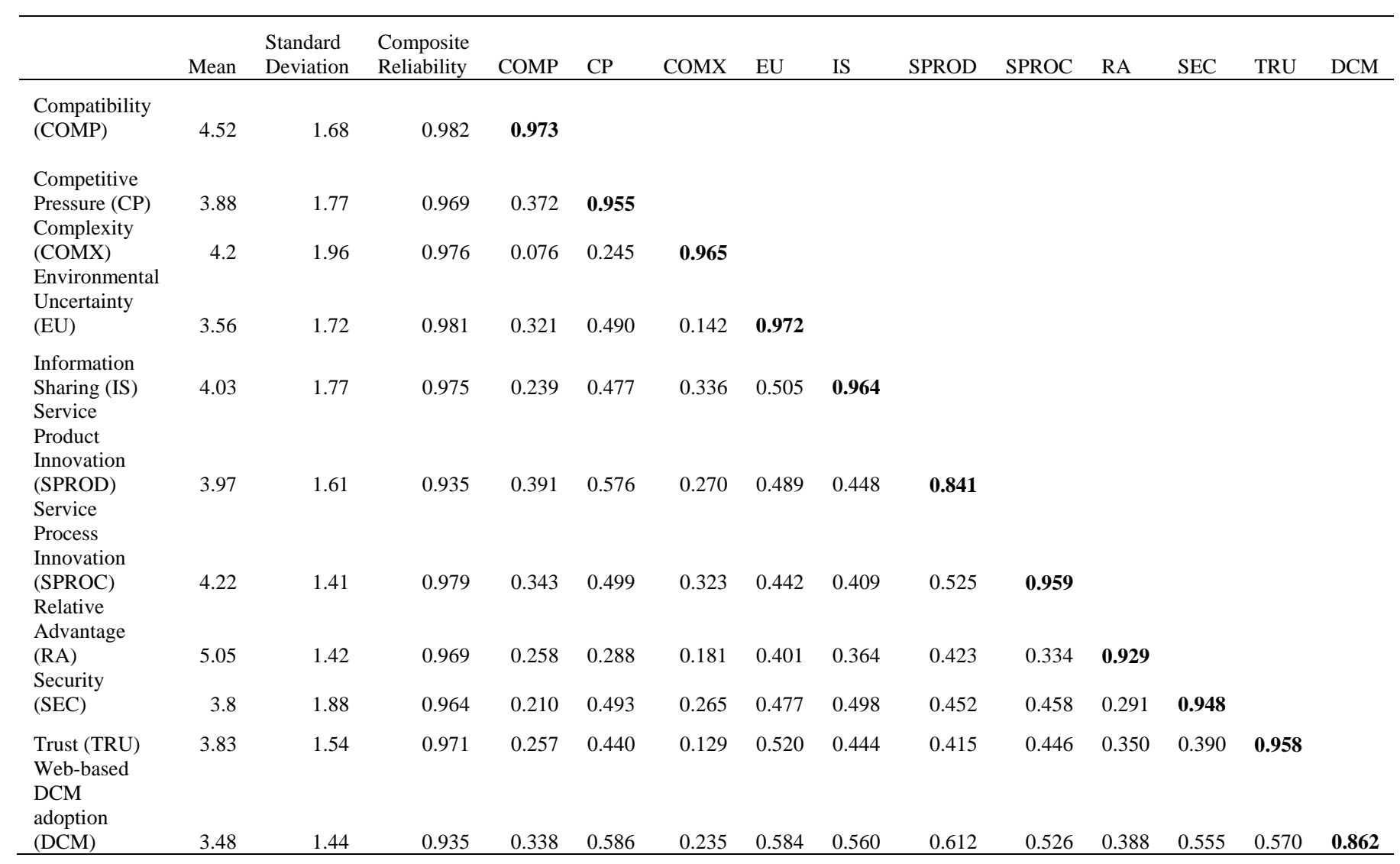


Table 2: Loadings of individual items

\begin{tabular}{|c|c|c|c|c|c|c|c|c|c|c|c|}
\hline & CP & COMP & OMX & EU & IS & SPROC & SPROD & RA & SEC & TRU & DCM \\
\hline CP1 & 0.965 & 387 & 0.253 & 0.520 & 0.503 & 0.554 & 0.517 & 0.300 & 0.499 & 0.460 & 0.623 \\
\hline & & & & .440 & & & & & & .382 & .513 \\
\hline CP3 & 0.955 & & & 0.435 & & & & & .493 & .412 & .530 \\
\hline & 0 & 972 & & 0.304 & 234 & & & 236 & 218 & 234 & 324 \\
\hline COMP2 & 0.377 & & & & & & & & & & 0.335 \\
\hline СОМР3 & 0.347 & & & 0.325 & & & & & & 0.243 & 0.326 \\
\hline COMX1 & & & & & & & & & & & 0.257 \\
\hline COMX2 & 0.216 & 0.053 & & 0.094 & & & & & & 0.107 & 0.204 \\
\hline COMX3 & 0.241 & & & & & & & & & & 213 \\
\hline EU1 & 0.48 & & & 0.97 & & & & 0.426 & & 0.504 & 0.579 \\
\hline EU2 & & & & & & & & & & 512 & 567 \\
\hline EU3 & 0 & 328 & & 0.966 & & & & 0.332 & 0.452 & 0.500 & 0.555 \\
\hline IS1 & & & & 0.498 & & & & & & & .529 \\
\hline IS2 & & & & 0.4 & & & & & & 450 & 0.529 \\
\hline IS3 & & & & & & & & & & 411 & .560 \\
\hline & 0.52 & & & & & & & & & .421 & 0.599 \\
\hline & 0.498 & 0.318 & & 0.465 & & & & & & .401 & 0.578 \\
\hline & 0.533 & & & & & & & & & 389 & 0.574 \\
\hline & 0.446 & 0.312 & & 0.335 & & & & 0.277 & & .235 & 0.421 \\
\hline & & & & & & & & & & & \\
\hline SPROC6 & 0.453 & 0.333 & 0.249 & 0.384 & & & 382 & 296 & & 309 & 0.447 \\
\hline & & & & & & & & & & & 472 \\
\hline & & & & & & & & & & & 0.495 \\
\hline SPROD3 & 0.468 & & & 0.414 & & & & 296 & 453 & .436 & 0.514 \\
\hline & & & & & & & & & & & 0.531 \\
\hline RA1 & 0.214 & 0.212 & 0.135 & 0.368 & 0.288 & 361 & 281 & 0.937 & 0.264 & 0.283 & 0.325 \\
\hline & & & & & & & & & & & 0.338 \\
\hline RA3 & 0.250 & 0.232 & 0.147 & 0.323 & 0.311 & & 0.280 & 0.917 & 0.272 & 0.282 & 0.335 \\
\hline & & & & & & & & & & & 0.378 \\
\hline & & & & & & & & & & & 0.411 \\
\hline SEC1 & & & & & & & & & & 0.367 & 0.519 \\
\hline SEC2 & & & & 0.423 & & & & & & 0.356 & 0.515 \\
\hline SEC3 & 0.482 & 0.206 & 0.299 & 0.499 & 0.470 & 427 & 0.470 & 0.277 & 0.937 & 0.384 & 0.541 \\
\hline & & & & & & & & & & 0.962 & 0.574 \\
\hline TRU2 & 0.407 & 0.232 & 0.104 & 0.496 & 0.413 & 0.368 & 0.391 & 0.327 & 0.354 & 0.953 & 0.523 \\
\hline TRU3 & 0.450 & 0.237 & & 0.504 & 0.421 & 0.407 & 0.449 & 0.316 & 0.386 & 0.959 & 0.540 \\
\hline DCM1 & 0.590 & 0.307 & 0.270 & 0.600 & 0.569 & 0.595 & 0.497 & 0.430 & 0.521 & 0.565 & 0.942 \\
\hline & & & & & & & & & & 0.519 & 0.926 \\
\hline DCM3 & 0.551 & 0.304 & 0.284 & 0.558 & 0.580 & 0.568 & 0.477 & 0.387 & 0.543 & 0.553 & 0.922 \\
\hline DCM4 & 0.434 & 0.247 & 0.047 & 0.405 & 0.373 & 0.423 & 0.451 & 0.204 & 0.371 & 0.402 & 0.765 \\
\hline DCM5 & 0.364 & 0.340 & 0.019 & 0.366 & 0.303 & 0.434 & 0.366 & 0.227 & 0.360 & 0.388 & 0.731 \\
\hline
\end{tabular}


Table 3: PLS path modelling results

\begin{tabular}{ccc}
\hline & $\begin{array}{c}\text { Path } \\
\text { Coefficient }\end{array}$ & Hypothesis \\
\hline Relative advantage -> Web-based DCM integration adoption & 0.071 & Rejected \\
Complexity -> Web-based DCM integration adoption & 0.010 & Rejected \\
Compatibility -> Web-based DCM integration adoption & 0.040 & Rejected \\
Security -> Web-based DCM integration adoption & $0.098^{*}$ & Accepted \\
Competitive pressure -> Web-based DCM integration adoption & $0.119^{*}$ & Accepted \\
Trust -> Web-based DCM integration adoption & $0.148^{*}$ & Accepted \\
Information sharing -> Web-based DCM integration adoption & $0.089^{*}$ & Accepted \\
Environmental uncertainty -> Web-based DCM integration adoption & $0.098^{*}$ & Accepted \\
Web-based DCM integration adoption -> Service process innovation & $0.540^{*}$ & Accepted \\
Web-based DCM integration adoption -> Service product innovation & $0.614^{*}$ & Accepted \\
\hline
\end{tabular}

Note: ${ }^{*} \mathrm{p}<0.05$ 